\title{
Let Your Success be BIIG: A New Paradigm for Problem-Solving in Science
}

\author{
C. N. Hiremath ${ }^{*}$ \\ Geo/Physical Sciences, Fitchburg State University, Fitchburg MA, USA \\ *Corresponding author: cnhiremath@gmail.com
}

Received February 26, 2015; Revised March 26, 2015; Accepted March 28, 2015

\begin{abstract}
Several problem-solving formats are used by the authors of various Physics textbooks. These can be best summarized as - decode, solve, and analyze. Despite the differing formats, each textbook provides an explanation for each step, however in the process it fails to clearly mention the finer details or attributes of each step in arriving at the solution. The objective of this study was to develop a streamlined process in problem-solving that enhances the students' learning experience in science. The BIIG problem-solving strategy is a new method of approaching real-world word problems in science in a simple, rational way with clarity and sufficient depth. The thought process in the BIIG method consists of four elements represented by four letters: "B" is associated with the numbers and units, "I" is associated with the variables, next "I" is associated with the contextual information, and "G" is associated with the actual presentation of the solution. The elements described in this article can be applied to any problem-solving format, thereby making it a universal method. Based on both internal and external empirical evidence, it shows that the model is supportive for the students' problem solving skills. The results indicate that starting with an initial interest level in Physics of only 28\%, the students developed appreciation for the subject significantly (76\%) and were highly satisfied with the assessment of their work (87\%). The BIIG problem-solving method provides much needed skills for improving science education from K-12 schools to colleges, universities and institutions worldwide.
\end{abstract}

Keywords: BIIG method, problem solving, analytical skills, science education innovation, word problem steps

Cite This Article: C. N. Hiremath, "Let Your Success be BIIG: A New Paradigm for Problem-Solving in Science.” International Journal of Physics, vol. 3, no. 3 (2015): 113-119. doi: 10.12691/ijp-3-3-4.

\section{Introduction}

This study transpired from the researcher's observation teaching various algebra-based or calculus-based Physics courses to science, engineering, and pre-medical students using different textbooks over the years. As discerned, there are several problem-solving formats used by the authors of various Physics textbooks (Table 1). These formats can be broadly generalized as - decode, solve, and analyze. The first step is usually associated with decoding the problem and is often labeled as - prepare, model, visualize, approach, or set-up. The second step commonly involves solving of the problem, which is labeled as solution, solve, or execute. By and large, the last step involves the analysis of the solution, which is labeled as insight, assess, note, or evaluate. Irrespective of these formats, there is a general explanation provided for each step but the finer details or attributes for each step are not clearly mentioned. These models simply need improvement. What comes in pairs? When does one convert into desired units? In which step does one focus on the variables? Have the variables been used consistently? Where does one need to be specific or where does one need to be verbose? How does one present one's final answer? How does one demonstrate that one knows the subject? These questions led to the formation of the elements of the new method in problem-solving. The elements described in this article can be applied to any problem-solving format, thereby making it a universal method called as the BIIG problem-solving method.

Table 1. Examples of some Problem-Solving Formats

\begin{tabular}{ll}
\hline Format & Book \\
\hline $\begin{array}{l}\text { Picture, Strategy, } \\
\text { Solution, Insight }\end{array}$ & Physics [1] \\
$\begin{array}{l}\text { Prepare, Solve, } \\
\text { Assess }\end{array}$ & College Physics: A Strategic Approach [2] \\
$\begin{array}{l}\text { Approach, Solution, } \\
\text { Note }\end{array}$ & Physics for Scientists and Engineers [3] \\
Identify, Set-up, & University Physics [4] \\
$\begin{array}{l}\text { Execute, Evaluate } \\
\text { Model, Visualize, }\end{array}$ & Physics for Scientists and Engineers: A \\
Solve, Assess & Strategic Approach [5] \\
\hline
\end{tabular}

The Cambridge Dictionary Online definition of "organizational skills" is: the ability to use time, energy, resources, etc. in an effective way so that you achieve things you want to achieve. And the Merriam-Webster Dictionary definition of "positive attitude" is: a way of thinking and behaving that people regard as friendly, kind, good, etc.

Some of the most effective and desirable characteristics of an efficient individual include good organizational skills and a positive attitude. Good organizational skills 
are essential in every aspect of life, and possession of these skills represents clarity of thinking. Overtime, an initial conscious and repetitive effort can lead to good habits [6].

Like organization, a positive attitude is also a crucial ingredient that can make a world of difference in every aspect of one's life [7]. For example, there is a difference between greeting a person with a positive attitude and without. An interaction which is finite and just to the point is cold, awkward and uncomfortable. On the other hand, warmer and friendlier interactions produce a deeper connection resulting potentially in a more lasting relationship.

Generally speaking, overall, we have been solving problems in science in a rational, methodical way [8]. However, the finer details and the attitude with which we should be solving science problems have not yet received much attention $[9,10,11,12,13]$. Based on the above, some desirable characteristics of an effective individual, the proposed BIIG problem-solving method aids in easily arriving at the correct solution.

\section{Exercise}

People often describe science subjects as difficult and challenging. Some students are intimidated especially by Physics [14]. A teacher can amplify the student's like or dislike of the subject [15]. It is possible to convert the dislike for the subject into lasting passion as will be clear from the following example. In a class room, as a part of introducing himself or herself every student gives example of an item that was not found in its appropriate location and expresses how he/she reacted to it. Interestingly, the examples include incidents of an airplane on a highway, a calculator in a pool, a wallet in a freezer, ketchup on the windshield, and the like. This simple exercise by the teacher and the students not only serves as an ice-breaker, but it also sets the tone for the course and sends a powerful message about the importance of staying organized while solving complex problems.

Sir Isaac Newton himself stated that the scientific knowledge of physical things must be considered mathematical, in that it is treated through mathematical reasoning [16]. Physics is mathematical in its formulation and plays a pivotal role in all the natural sciences. There was a difference in the perception of students and teachers when it came to the difficulties experienced by the students in Physics [14]. In that study, the teachers indicated that Physics cannot be learned without a good background in mathematics. On the other hand, the students indicated that not having good mathematics background does not make Physics difficult.

The researcher also observed that the students faced difficulties in solving lengthy word-problems in physics. In an effort to elevate some of these difficulties, the researcher's teaching approach naturally evolved over the years, which led to the formulation of the new method.

What is the BIIG problem-solving strategy in science? The BIIG strategy is a method of approaching real-world word problems in science in a simple, rational way with clarity and sufficient depth. The thought process in the BIIG method consists of four elements: the first element is the letter " $\mathrm{B}$ " which is associated with the numbers and units, the second element is the letter "I" which is associated with the variables, the third element is another letter "I" which is associated with the contextual information, and the fourth element is the letter " $G$ " which is associated with actual presentation of the solution as outlined in Figure 1.

\section{Think BIIG}

\begin{tabular}{|c|c|c|c|}
\hline Elements & Representation & Purpose & Example \\
\hline B & Buddies & Number(s) and Unit(s) & $60 \mathrm{~m} / \mathrm{s}$ \\
\hline I & Identification & What they represent & $v=60 \mathrm{~m} / \mathrm{s}$ \\
\hline I & Isolation & Contextual information & $v_{c a r}=60 \mathrm{~m} / \mathrm{s}$ \\
\hline G & Gourmet & Finishing touches & $\begin{array}{c}\text { The velocity of the car, } \\
v_{c a r}=60 \mathrm{~m} / \mathrm{s}\end{array}$ \\
\hline
\end{tabular}

Figure 1. The four elements of the BIIG problem-solving method

The dictionary definition of "problem-solving" is: the thought process involved in solving a problem; the process of using your mind to consider something carefully; thinking that brings together information focused on problem-solving; problem-solving that involves numbers or quantities. The term "qualitative" is defined as: involving or relating to distinctions based on quality or quantities. And the definition of "analytical" is: expert in or using analysis, especially in thinking.

The BIIG method is needed to develop an aptitude for dealing with qualitative analytical questions. Since, many students are not trained enough; it is needed to develop a strategy to make qualitative analytical problem-solving student-friendly. After an extensive literature search, it was clear that no other methodology, if any, came close to the BIIG method.
The BIIG method is relevant to physical science and engineering. The physical science is defined as a branch of natural science that studies non-living, in contrast to life science. It includes physics, astronomy, chemistry, and earth science. Many branches of physical science also study biological phenomena. The discipline of engineering is extremely broad and it emphasizes on the application of science.

The objective of this study was to improve and enrich the students' learning experience through a streamlined problem-solving process in science. From a scientific perspective, a detailed description of the problem-solving method has been presented here. Based on empirical evidence, both internal and external, this objective has been successfully achieved through the BIIG method. This 
academic article was intended for all teachers and students on the whole because of its potential educational benefits.

The main research questions were:

1. Before the course began, what was the students' initial interest level in the subject?

2. Did the students develop appreciation for the subject?

3. Were the students satisfied with the assessment of their work?

4. Was the method beneficial to all students? What was their feedback?

\section{Methods}

A word problem in science is usually stated in a layman's language and consists of known facts and numbers. Based on the given information, a few unknown values need to be determined using standard formulae. Let us consider the following word problem.

Problem: Suppose the distance between Boston and New York City is 202 miles and you are driving at 50 miles per hour. How long will it take to reach the destination? Will you reach within 3 hours?

By now, one may have gone through the essential steps on the basis of the intuition alone, by dividing the two numbers appropriately and arriving at the right answer instantly. The final answer is important, but one must pay attention to the path taken because the path provides examples of key steps taken for enforcing the various elements of the concept. A strong foundation is thus laid, which leads to the individual mastery of the subject matter. Hence let us explore this real-world word problem using the BIIG method.

\section{Buddies}

The first element in the BIIG method focuses on the "buddies". The dictionary definition of the word "buddy" is: a partner, a good friend, a comrade, a companion. This element encourages students to "buddy-up" the numbers with their units; numbers are absolutely meaningless in a word problem without their units. Imagine going to the bank and politely saying to the teller: "May I please have two?" The teller would certainly seek clarification. "Do you mean pennies, dimes, quarters, or dollars?” In the problem above, we first scout for the numbers presented to us in the problem and then pair them up with their corresponding units: 202 miles and 50 mph. It is important to convert the units to a system of units that is recognized around the world, referred to as SI units. There are, however, certain assumptions that are not explicitly stated but are crucial to finding the right solution. In this problem, it is assumed that the person is driving at a steady speed, which means there is no obstructing traffic, or any weather or human related delay.

\section{Identification}

The second element of the BIIG method involves the identification of what each buddy represents. This step is most important as it sets the tone of how the rest of the problem solving process will play out. If the student does not understand the information given in the problem and what each piece represents, then what the student does afterwards will be for naught. Therefore, it is imperative that a student is able to decode the problem correctly. Continuing with the example, what measurement does "mile" represent in 202 miles? A mile is a way of measuring distance. Although the units of the value are known, it is necessary to recognize what these units measure. In this case, mile is a measurement of distance, $d$. And $\mathrm{mph}$ is a measure of speed, s. Hence, distance, $d=$ $202 \mathrm{mi}$ and speed, $s=50 \mathrm{mph}$. As warned, a disaster is waiting to happen when variables are incorrectly assigned as, $s=202 \mathrm{mi}$ and $d=50 \mathrm{mph}$.

\section{Isolation}

Isolation is the incorporation of context based information into the identification element. This element usually involves making a distinction between two characteristics such as a start and finish, or initial and final measurement, commonly designated using subscripts. As we advance through the problem, we must recognize which value of distance is being addressed. In most problems, it is not unusual to encounter more than one measurement relating to different situations. In our example, at the start of the journey, the distance read by the mile-counter in Boston will be 0 miles, and when the journey is completed, the distance read upon reaching New York City will be 202 miles. So which distance is relevant: 0 miles, or 202 miles? Does the provided distance in the example correspond to when the person is in New York City? The clue once again lies within the problem. Clearly, the distance corresponds to the distance at the finish line. Therefore, at the destination the distance is $d_{\text {finish }}=202 \mathrm{mi}$.

\section{Gourmet}

Last but not the least, the element G is the "Gourmet" piece of the BIIG method. The dictionary definition of the word "gourmet" is: a person with discriminating tastes, expert, excessively refined, sophisticated, finest. So what are we looking for? The problem concludes with: "How long will it take to reach the destination and will you reach within 3 hours?" This means the final task is to calculate the total time taken. Once all of the information is extracted from the problem as carefully as possible using the first three elements of the BIIG method, finally the solution using all known quantities should be determined. In order to follow the organized method, it is important to state which formula is used:

$$
\text { time }=\frac{\text { distance }}{\text { speed }}
$$

This is necessary not only for clarity of the mind, but also to make sure that it correlates with the problem and that all the variables are used correctly. To get the information for time, we divide the total distance by the speed:

$$
t_{\text {finish }}=\frac{d \text { finish }}{\mathrm{s}}=\frac{202 \mathrm{mi}}{50 \mathrm{mph}}=4.04 \text { hours }
$$

Now we have a definite value for $t_{\text {finish }}=4.04$ hours. When a calculator is used, it may display many digits. But are they all meaningful? So, one has to consider the precision of tools used in the measurements. Here in this example, the "weakest link" is the measurement of speed with a reliability of 1 digit for $50 \mathrm{mph}$, which means the final answer must reflect one significant figure, 4 hours.

Further, the final solution of the word problem should be provided in a way the problem was presented and is understandable by someone who does not know what is meant by " $t_{\text {finish }}$ ". And this is where the "gourmet" piece of 
the BIIG method plays a part. It adds the finishing touches to the final answer, with reliably known digits. What is $t_{\text {finish }}$ ? It is the time taken to reach the finish line. We can consolidate this information in a simple yet elegant way as follows: the time taken, $t_{\text {finish }}$, to reach the destination is 4 hours. The final analysis is part of the gourmet element as well. Since the time taken is more than the specified time (3 hours), you will not reach the destination within that time. This clearly demonstrates a solid understanding of the problem, the thought process, the solution, as well as final analysis.

\begin{tabular}{|c|c|}
\hline Example & $\begin{array}{l}\text { Reference: } \\
s=\Delta x / \Delta t \quad ; \quad 1 m i=1609 \mathrm{~m} \\
\text { Problem: } \\
\text { Suppose the distance between Boston and New York City is } 202 \\
\text { miles and you are driving at } 50 \text { miles per hour: How long will it } \\
\text { take to reach the destination? Whll you reach within } 3 \text { hours? }\end{array}$ \\
\hline Common Mistakes & Best Practice \\
\hline $\begin{array}{l}\text { Solution: } \\
\text { We have, } \\
d=202 \mathrm{mi}\end{array}$ & 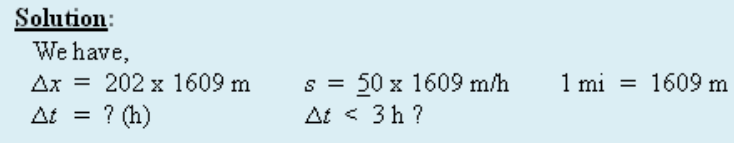 \\
\hline $\begin{array}{l}\text { Using the equation, } \\
\qquad \begin{aligned} \Delta t & =\Delta x / \mathrm{s} \\
& =(202 \mathrm{mi}) /(50 \mathrm{mi} / \mathrm{h}) \\
& =4.04\end{aligned}\end{array}$ & $\begin{array}{l}\text { Using the speed equation and solving for time interval, } \\
\qquad \begin{aligned} \Delta t & =\Delta x / s \\
& =(202 \times 1609 \mathrm{~m}) /(50 \times 1609 \mathrm{~m} / \mathrm{h}) \\
& =4.04 \mathrm{~h}\end{aligned}\end{array}$ \\
\hline you will not reach the destination within that time. & $\begin{array}{l}\text { The time taken to reach the destination is: } 4 \mathrm{~h} \\
\text { Since, the time taken is more than } 3 \mathrm{~h} \text {, } \\
\text { you will not reach the destination within that time. }\end{array}$ \\
\hline
\end{tabular}

Figure 2. Comparison of a solution with common mistakes and the recommended solution

A solution with common mistakes is compared with the recommended solution in Figure 2. The BIIG problemsolving method is neither time consuming nor lengthy. Since searching through organized information yields faster and more efficient results, it is wise to approach word problems by first organizing the information, then attempting to arrive at the solution. It would certainly be risky to do it any other way.

\section{Validation}

The data for the study included five Physics courses taught at the university level. To ensure data integrity, for all courses the syllabi were essentially same (except the dates); the same textbook was prescribed, and the class sizes were similar over the period of five years. The use of BIIG problem-solving method was also mentioned in the syllabi and the method was consistently used in the class for quizzes and exams including the final. Before the course began, the students completed the online survey (using SurveyMonkey) and expressed their initial interest level with options: "high", "neutral”, "low”, "hate it". At the end of the course, the data was collected from two separate sources, internal as well as external. In the internal class survey, the students were asked, "Did you appreciate/love this subject much more during/after this course?", and the options were: “yes", "no”. From the external state-wide student evaluation of the course, called the Massachusetts State College System (MSCS) which was administered by the University, the data for "The instructor's methods of evaluating my work were appropriate" was extracted from the assessment section, and the options were: "strongly agree”, "agree”, "neutral”, “disagree”, "strongly disagree”, "not applicable”.

\section{Students' appreciation and satisf action}

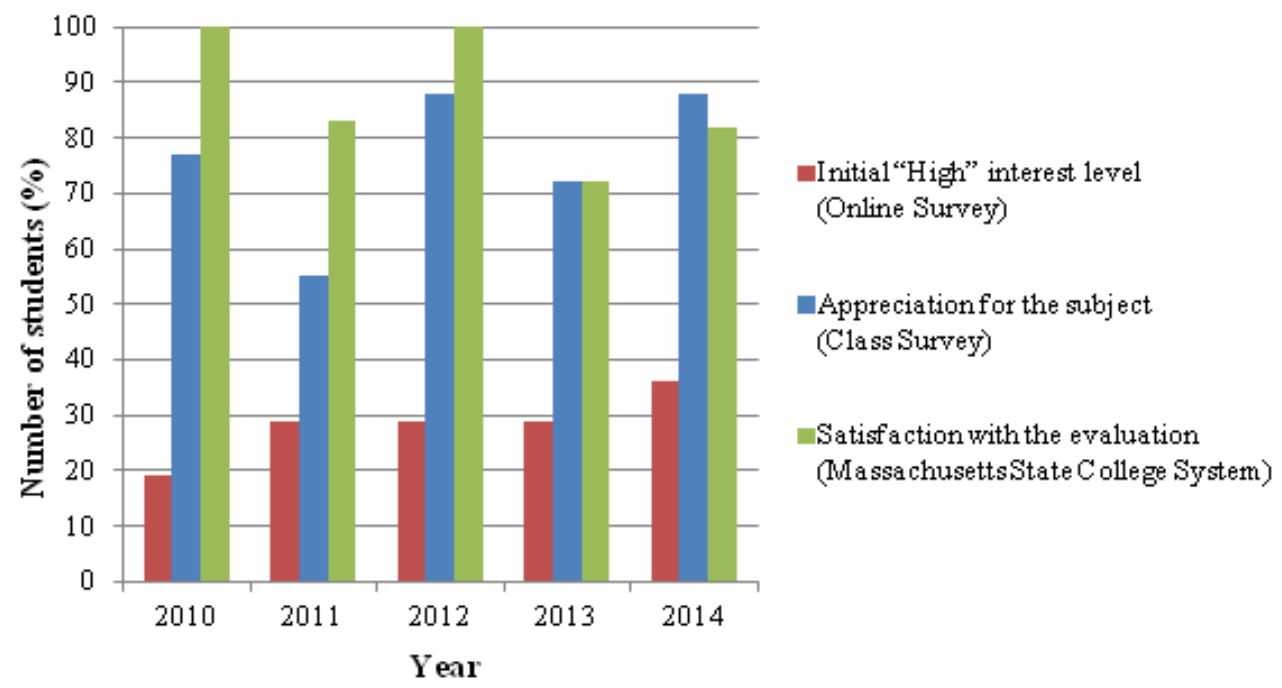

Figure 3. Comparison of students' learning experience at the beginning and end of the course 


\section{Results and Discussion}

\section{BIIG success}

The researcher developed this BIIG method of solving word problems and has successfully used with students for several years at various levels of education including universities, colleges, and high-schools. A comparison of students' learning experience at the beginning and end of the course shows significant and consistent improvement (Figure 3).

Based on the online survey taken before the course began, the initial "high" interest level had an average value of $28 \%$ (Table 2). Based on the internal class survey at the end of course, the students who developed appreciation for the subject rose significantly to an average of $76 \%$. And based on the external Massachusetts State College System, the evaluation revealed that students were highly satisfied with the assessment of their work and with an average of $87 \%$.

Table 2. Students' appreciation for the subject and satisfaction with the assessment

\begin{tabular}{cccc}
\hline Course & $\begin{array}{c}\text { Initial } \\
\text { “high” } \\
\text { interest level }\end{array}$ & $\begin{array}{c}\text { Appreciation for } \\
\text { the subject } \\
\text { developed }\end{array}$ & $\begin{array}{c}\text { Satisfaction with } \\
\text { the evaluation of } \\
\text { student work }\end{array}$ \\
\hline Study 2010 & $19 \%(21)$ & $77 \%(22)$ & $100 \%(21)$ \\
Study 2011 & $29 \%(17)$ & $55 \%(18)$ & $83 \%(18)$ \\
Study 2012 & $29 \%(17)$ & $88 \%(16)$ & $100 \%(19)$ \\
Study 2013 & $29 \%(17)$ & $72 \%(18)$ & $72 \%(18)$ \\
Study 2014 & $36 \%(14)$ & $88 \%(17)$ & $82 \%(17)$ \\
\hline
\end{tabular}

The number in parenthesis indicates $\mathrm{N}$.

These significant improvements in positive learning experience and the consistency of results has unequivocally proved the BIIG problem-solving method successful. The testimonies of students are solemn attestation of the model (Table 3).

Table 3. Selected testimonies of students Student feedback

\begin{tabular}{ll}
\multicolumn{1}{c}{ Student feedback } \\
\hline 1 & $\begin{array}{l}\text { I have some good news for you: I no longer hate Physics! } \\
\text { I learned much more than I expected, and it made me like Physics } \\
\text { more. }\end{array}$ \\
3 & $\begin{array}{l}\text { I was worried to take Physics but you made it understandable and } \\
\text { enjoyable. }\end{array}$ \\
4 & Problem solving was extremely helpful. \\
5 & Now I feel like I have a firm grasp on all topics in Physics. \\
6 & The quizzing was very helpful and had a great teaching technique. \\
7 & $\begin{array}{l}\text { Certainly provided a new look on Physics, and a new found respect } \\
\text { for the subject. }\end{array}$ \\
\hline
\end{tabular}

Initially, like everything else, the process might seem slow and laborious. Once the essential elements have been internalized, the students who struggled with problemsolving before learn to incorporate the best practices in a seamless way and they find themselves focusing on mastering the subject (Table 3). Even highly able students find the BIIG method beneficial as they confidently venture into exploring more complex problems (see the student perspective).

\section{Student's perspective}

After working with the BIIG strategy for just a short time, it would seem as if no other way makes sense. The BIIG strategy will become second nature, because your brain simply would not want to go back to dealing with numbers in a disorganized, chaotic nature, and as soon as it becomes a habit, there is no "thinking" about it anymore. It just comes! If I ever amassed the patience necessary to teach, this would be the first method I would encourage my students to have. With a skill like this, no problem is too hard or too complex. It is all about organizing the ideas and being able to clearly see the other side of the tunnel, using formulas as our pathway.

Moreover, there are certain aspects that cannot be put in numbers, tables or figures. Over the course of the semester, there was rise in the confidence level of students, there was increased active participation in the class, and most importantly, there was a sense of calmness and brought many smiles on the faces of students.

\section{A practical approach}

By assigning specific points or percentage for numerous "checkpoints", the use of this practical approach for open-response word problems allows a student to make sure the essential steps are being followed, and gives students an opportunity to earn partial credit even if the final answer is not correct (provided the steps were leading in the right direction). Each of the six "checkpoints" is listed in the Figure 4.

Note that the elements of BIIG problem-solving method for each "checkpoint" are clearly prescribed. In terms of the big picture, for each open-response problem the expectations set are high, clear, and achievable. The first three elements of this problem-solving strategy are extremely valuable for solving multiple-choice word problems as well. The practice template for problemsolving using the BIIG method and inclusive pedagogy that would benefit teachers as well as students on the whole has been included in Appendix 1.

The BIIG method makes the teacher-student communication easier as well. If the student asks on which areas he or she should be focusing on, instead of broadly saying the actual step such as decode, solve, and/or analyze, it is now possible to point precisely to which skills or aspects of the methodology the student should focus on: units and unit conversions (B), careful and consistent use of variables (Is), and mastery of concepts, names of important laws and formulae as well as proper analysis of the solution $(G)$.

\begin{tabular}{|c|c|c|}
\hline Format & Checkpoint & Entails \\
\hline \multirow{2}{*}{ Decode } & 1 & $\begin{array}{l}\text { Assigning of the known information to the corresponding variables, and } \\
\text { performing unit conversion }\end{array}$ \\
\hline & 2 & Assigning of the unknown information to the variable(s) \\
\hline \multirow{2}{*}{ Solve } & 3 & $\begin{array}{l}\text { Providing the description of the formula(e) and writing of the formula(e), and } \\
\text { including diagram(s) if needed }\end{array}$ \\
\hline & 4 & Showing the math clearly with consistent use of variables and units \\
\hline \multirow{2}{*}{ Analyze } & 5 & $\begin{array}{l}\text { Reporting the final answer with correct significant figures for the solved } \\
\text { (unknown) variable(s) }\end{array}$ \\
\hline & 6 & $\begin{array}{l}\text { Specifying the correct units, and performing the proper analysis of the solution } \\
\text { if needed }\end{array}$ \\
\hline
\end{tabular}

Figure 4. Checkpoints with their BIIG elements

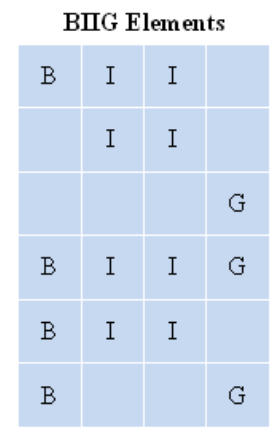




\section{Science Education Innovation}

The conventional problem-solving formats only have the vertical approach or one-dimensional approach. The BIIG method is two-dimensional with the vertical steps and the horizontal BIIG elements (see Figure 4). The new additional dimension provided by the BIIG elements represents the innovation in problem-solving.

Solving word problems improves scientific comprehension. The word problems help in the evaluation of students' understanding of the concepts. It is not a linguistic issue. It is not only a matter of meta-cognition, the awareness and understanding of one's own thought process, but a key aspect in solving problems correctly. Learning how to solve word problems should not simply be for the sake of getting a passing grade in the subject.

Numerical problems, which can be solved mathematically, are in a way a subset of qualitative analytical problems. Mathematical problem-solving does not necessarily include aspects of scientific problem-solving, such as, units, physical concepts, etc. Hence, mathematical problem-solving is in a way a subset of scientific problem-solving. Experimental problem-solving is a subset of scientific problem-solving as well. Therefore, the BIIG method is helpful in tackling several aspects of scientific problemsolving.

An engineering design cycle is important in science; science and engineering is crucial to real-world learning, and mathematical techniques are but a small part of that learning. Science education is much wider in content than mathematical skill, and it encompasses competence related to dispositions (attitudes and values), cross-functional skills and cognitive self-development. It needs a certain aptitude that can be honed only by training, and the BIIG method offers this opportunity by aiding in the development of cross-functional skills and cognitive self-development.

\section{Conclusion}

The BIIG problem-solving method is unique in that it forces us to concentrate on decoding a real-world word problem completely into meaningful parts and aids us in finding and applying the right formula to easily arrive at the correct solution. As desired, it places less emphasis on the memorization of factual detail and more emphasis on the understanding of concepts. Evidently, this method is beneficial in many ways as it aids students in honing skills in critical thinking, logical approach and attention to detail. As a method for organizing information it helps students avoid errors and sets them on a path to succeed. As long as the numbers are "buddied up" with their units, "identified" by the appropriate variables, "isolated" within the context, and the answer is presented "gourmet", or explained in terms of the original question, finding a solution to any complex problem will become seamless, understandable and enjoyable. This innovation in science education is effective regardless of whether the instructional approach is "passive" traditional learning or active inquiry-based and collaborative learning. Based on evidence from two different sources presented, this method has been unequivocally proved successful. Relative to the initial interest level for the subject, the students developed appreciation for the subject significantly and were highly satisfied with the assessment of their work. The implication of this clear outcome is that a skill as strong as this one becomes irreplaceable as it fosters a passion for learning and serves as a foundation for a new paradigm for problem-solving in any discipline of science worldwide.

\section{References}

[1] Walker, J. S. (2002). Physics. Prentice-Hall, Inc.

[2] Knight, R., Jones, B., \& Field, S. (2010). College Physics: A strategic Approach. Pearson Education, Inc., publishing as Addison-Wesley.

[3] Giancoli, D. C. (2009). Physics for scientists and engineers with modern physics. Pearson Prentice Hall.

[4] Young, H. D., Freedman, R. A. (2012). University Physics: with modern physics. Pearson Education, Inc., publishing as AddisonWesley.

[5] Knight, R., (2013). Physics for scientists and engineers: A strategic Approach. Pearson Education, Inc.

[6] Gulacar, O., Bowman, C. R., \& Feakes, D. A. (2013). Observational investigation of student problem solving: The role and importance of habits. Science Education International, 24(2), 344-360.

[7] Rukavina, S., Zuvic-Butorac, M., Ledic, J., Milotic, B., \& Jurdana-Sepic, R. (2012). Developing positive attitude towards science and mathematics through motivational classroom experiences. Science Education International, 23(1), 6-19.

[8] Handelsman, J., Ebert-May, D., Beichner, R., Bruns, P., Chang, A. DeHaan, R., Gentile, J., Lauffer, S., Stewart, J., Tilghman, S.M., \& Wood, W. B. (2004). Scientific Teaching. Science, 304, 521522

[9] Bonner, J. J. (2004). Changing Strategies in Science Education. Science, 306, 228.

[10] Wood, W. B., \& Gentile, J. M. (2003). Teaching in a Research Context. Science, 302, 1510.

[11] Sung, N. S., Gordon, J. I., Rose, G. D., Getzoff, E.D., Kron, S. J., Mumford, D., Onuchic, J. N., Scherer, N. F., Sumners, D. L., \& Kopell, N. J. (2003). Educating Future Scientist. Science, 301, 1485.

[12] Wood, W. B. (2009). Revising the AP Biology Curriculum. Science, 325, 1627.

[13] Koedinger, K. R., Booth, J. L., \& Klahr, D. (2013). Instructional Complexity and the Science to Constrain It. Science, 342, 935-937.

[14] Ornek, F., Robinson, \& W. R., Haugan, M. R. (2007). What Makes Physics Difficult? Science Education International, 18(3), 165-172.

[15] Kapucu, S. (2014). Salient beliefs of pre-service primary school teachers underlying an attitude "liking or disliking physics". Science Education International, 25(4), 437-458.

[16] Gingras, Y. (2001). What did Mathematics do to Physics? History of Science, 39, 383-416. 


\section{Appendix 1}

Practice template for problem-solving using the BIIG method

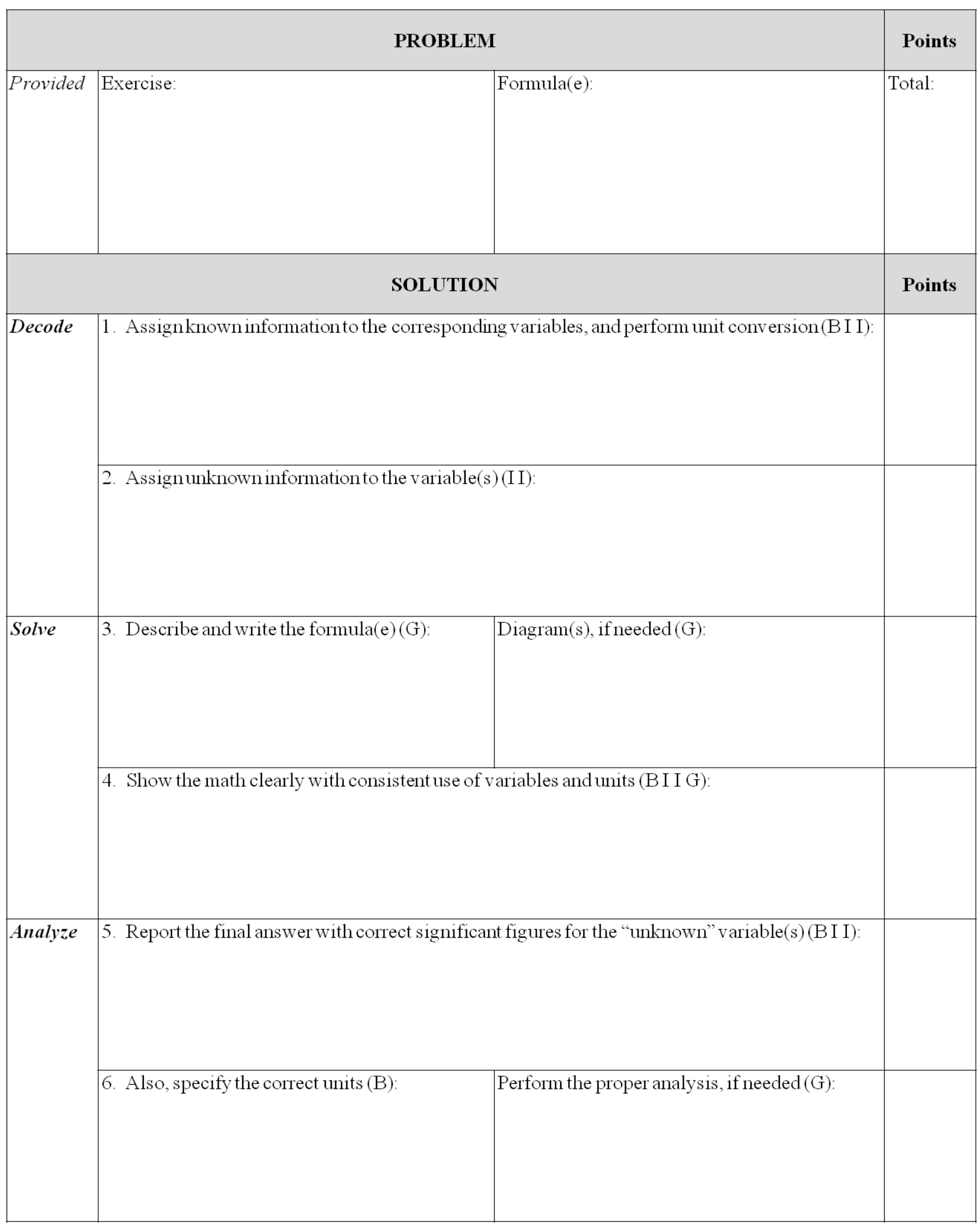

(c) Dr. Hiremath (2015) 